\title{
Using an Educational Consensus to Reach Educational Technology Tipping Point
}

\author{
Roger Carlsen \\ Department of Educational Leadership, Wright State University, Dayton, Ohio, USA, \\ roger.carlsen@wright.edu
}

\section{INTRODUCTION}

In the United States, the use of educational technology is mandated by accredited teacher preparation programs and by state accrediting departments of education. Yet the majority of teacher education faculty fail to infuse educational technology procedures into their courses at substantial levels (Mitchell, Dipetta \& Kerr, 2001), and teachers fail to infuse technology into their teaching (Anderson \& Speck, 2001). For educational technology to become firmly entrenched in our educational systems, educational technology must become a part of the culture of our schools. This paper reports the attitudes and opinions gathered from interviews, questionnaires, and classroom artefacts from two groups of practicing teachers $(n=31)$ enrolled in a 'teacher leader' graduate program. This paper represents only the first phase of a census-like assessment of a much larger group of undergraduate $(n=133)$ students, graduate level teachers $(n=92)$, information technology directors and college faculty $(n=32)$ from twelve colleges and universities.

\section{NEED}

During initial class discussions no pervasive plans for the ubiquitous infusion of technology into education were reported in any of the schools from which a group of Teacher Leader graduate students $(n=31)$ hailed. In a follow-up session the teachers were asked to complete an educational technology questionnaire indicating their experiences and opinions related to

The original version of this chapter was revised: The copyright line was incorrect. This has been corrected. The Erratum to this chapter is available at DOI: 10.1007/978-0-387-35701-0_35 
the use of educational technology and the Internet. The Tipping Point, a theory put forth by Gadwell (2000), appeared to be an appropriate model for educational technology development in all the schools from which the participating teachers came. The teachers' positions were evaluated for preparedness to teach using technology. Secondly, a determination was made relative to each teacher's ability to play one of Gadwell's leadership roles as Connector, Maven, or Salesperson.

Malcolm Gadwell's basic principle for achieving the Tipping Point in a learning community is based on the idea that a social epidemic will take place when there are sufficient or strong enough individuals to bring about change. He viewed this as being a critical point akin to critical mass when a culture changes. His idea of the Tipping Point differed from critical mass somewhat because he believed that the Tipping Point need not be arrived at gradually. Gadwell also identified three roles that would contribute to this change, the Connector, Maven, and Salesperson. The Connector was an individual with special talent to bring people together to work well in teams. Mavens were pivotal because they, unlike geeks or gurus, possessed both knowledge and social ability. Mavens give freely to colleagues. Mavens mentor and work alongside those with less developed knowledge and skills. Finally, Gadwell identified Salespeople who usually exhibit the characteristics of exuberance and enduring optimism. Salespersons, however, often fail to succeed without Mavens and Connectors.

\section{RESULTS}

Teachers were asked if they could provide a metaphor for the use of technology or the Internet in their educational programs. Ninety-three percent $(n=29)$ of the respondents produced neutral or positive metaphors such as technology offers students "windows to the future" while two (7\%) offered dismal metaphors. The most negative metaphor was that, "computers are the root of all evil and computers are the future."

Eight teachers $(26 \%)$ had personal web pages while only five $(16.67 \%)$ reported that their students had access to either personally developed or school maintained resource pages. These percentages with access to such resources were substantially lower than those reported by Levin and Arafeh (2002). The older their students, the more frequently teachers felt that the students knew more than the teachers. These findings were especially interesting because $18(60 \%)$ felt more knowledgeable than their colleagues.

All but four teachers replied to the request that they report how they use computers or the Internet creatively. The two most common responses were as a word processor $(n=7)$ and to create PowerPoint presentations $(n=3)$. 
Several individuals did mention activities such as morphing digital pictures, creating maps, going on scavenger hunts, and creating poetry art.

There was wide agreement $(96.7 \%)$ on using Internet filters, with only two secondary teachers reporting that filters should be used only with young students. Three teachers did not answer this question because their students were not permitted on the Internet. It is interesting to note that this position, at least at the secondary level, is contrary to that of the American Library Association (2002).

Most teachers $(n=28,90.3 \%)$ used e-mail on a daily basis. Five teachers (16.1\%) used e-mail for communication with friends or their college professors, but not in their schools or with their students. Only one teacher did not have access to the Internet outside school. Twelve teachers $(38.7 \%)$ used instant messaging software, while only $4(12.9 \%)$ participated in chat. Overwhelmingly, most teachers $(n=30,96.7 \%)$ felt that the Internet benefited them greatly, while far fewer $(n=19,63.3 \%)$ reported that their students benefited from using the Internet.

The feelings that these teachers reported towards using technology and the Internet were positive. Only six (19.4\%) reported feeling frustrated or uncomfortable with technology. Four teachers (12.9\%) reported feeling moderately comfortable but they felt that they needed more time and training. Twenty-one $(67.7 \%)$ reported feeling that they were comfortable or very comfortable with their use of technology and the Internet in their educational programs.

Only one teacher from this group possessed sufficient knowledge, skills and inclination to be identified as a Maven. Other teachers demonstrated potential Connector or Salesperson traits. Such traits may only be visible when classrooms are constructivist rather than traditional. Two teachers exhibited negative responses and thus might be viewed as being negative Salespersons.

\section{CONCLUSIONS AND FUTURE ACTIVITIES}

This paper examined practicing teachers who reported feeling comfortable with their technology and Internet use, but who appeared, in many cases to lack knowledge, skill, or in many cases the ability to use technology creatively. Few teachers were ready to accept the roles of Maven or technology Salespersons. This report appears to confirm a recent report identifying a digital disconnect between schools and their students (Levin \& Arafeh, 2002). This disconnect gap appears to grow wider based on the age of the students. Few practicing teachers that we evaluated, however, saw 
their technology or Internet abilities deficiencies as being sufficiently inadequate for a call to action.

Several current teachers reported feeling frustrated and confused. Thus it would appear that a small core of teachers remains reluctant to participate and may view technology with hostility. When Carroll (2000) asked the question, "If we didn't have the schools we have today, would we create the schools we have today?" one wonders if he perhaps should have also referred to teacher preparation, teacher in-service, school administrators, and school infrastructure.

This is only a preliminary investigation to help identify issues and questions for a larger census of education graduate and undergraduate students, college faculty, and information technology directors. Because of our current investigative schedule we are limited to what we can add relative to this larger study. It does appear as though undergraduate preservice teachers' knowledge and skills relative to technology and the Internet will differ substantially from those of current practicing teachers.

\section{REFERENCES}

American Library Association (2002). Plain Facts About Internet Filtering Software. Retrieved from http://www.pla.org/publications/technotes/technotes_filtering.html

Anderson, R. \& Speck, B. (2001). Using Technology in K-8 Literacy Classrooms. Upper Saddle River: Prentice-Hall.

Carroll, T. G. (2000). If we didn't have the schools we have today, would we create the schools we have today? Contemporary Issues in Technology and Teacher Education, 1(1). Retrieved from http://www.citejournal.org/vol1/iss1/currentissues/general/article1.htm

Gadwell, M. (2000). The Tipping Point: How Little Things Make a Big Difference. Boston, MA: Little-Brown.

Levin, D. \& Arafeh, S. (2002). The Digital Disconnect: The Widening Gap Between Internet Savvy Students and Their Schools. Pew Internet \& American Life Project. Retrieved from http://www.pewinternet.org/reports/toc.asp?Report $=67$

Mitchell, C., Dipetta, T. \& Kerr, J. (2001). The frontier of web-based instruction. Education and Information Technologies, 6(2), 105-121. 